\title{
12
}

\section{Redesigning Procurement Strategies for Complex Policy Spaces}

\author{
Ann Nevile
}

\section{Introduction}

In her summing up speech on the National Disability Insurance Scheme (NDIS) Bill, the then parliamentary secretary for disability noted that giving people choice and control over the care and support they receive is one of the ways in which Australia will give effect to the $U N$ Convention on the Rights of Persons with Disability (McLucas 2013). The right to choose is enshrined in the design of the NDIS, under which, for the first time, individuals with disability will be given a choice over the type of services they receive and who delivers those services. However, the NDIS is not designed as a 'stand-alone' system and is expected to operate in conjunction with 'mainstream' disability services, such as employment. In this chapter, I argue that, despite commitments from successive Australian governments to reduce the administrative burden placed on disability employment service providers, the current contracting regime continues to constrain agency capacity to deliver flexible, individualised services - a situation that needs to change if Australians with disability who wish to work in open employment are to realise the economic, social and health benefits of employment that the majority of Australians take for granted. 
The remainder of this chapter briefly discusses the design features of the current system, before presenting the evidence base for the assertion that introducing a person-centred approach will lead to better employment outcomes. The chapter then considers the suitability of an explicit voucher system, identifying three policy preconditions that need to be met before such a system can provide the requisite levels of choice and control.

\section{Disability employment services}

In Australia, government provision of mainstream employment services has been delivered through a mix of commercial and community or notfor-profit agencies since 1998. Since its inception, the Job Network ${ }^{1}$ has been an active labour market program in that unemployed individuals are required to actively look for work and accept suitable work if offered. Providers are selected through a competitive tender process and funded by an outcome-based funding model that requires achievement of milestones before payment is made. Agencies are contracted to provide services in a designated employment service area (ESA) and allocated a certain market share within that ESA. Future contracts and percentage of market share are dependent on an agency's ranking relative to other agencies, not just within their ESA, but also across the whole of Australia. As well as assisting unemployed individuals to find work, employment service providers are required to report breaches of government requirements by jobseekers to Centrelink, a central government agency that manages all social security payments and provides residual employment services such as referrals to employment service providers. Unemployed individuals who are required to look for work are able to choose a service provider from among those operating within their ESA; however, the amount of publicly available information on the comparative performance of employment service providers is limited and Centrelink refers the majority of jobseekers to a particular provider. Service providers are obliged to accept all referrals from Centrelink unless they have reached 120 per cent of their allocated market share. Public spending

1 The Job Network was replaced in 2009 with a new generation of employment services known as Job Services Australia and, on 1 July 2015, Job Services Australia was replaced with jobactive, but the basic design elements remain the same. 
on labour market programs decreased after the introduction of the Job Network, and the prioritisation of cheaper, shorter interventions has led to a decrease in the cost per client (Wright 2008: 17). In a system where financial viability is achieved by adopting a 'high-volume/lowvalue' business model, agencies feel they are no longer able to make long-term investments in jobseekers or engage in truly innovative practices (Fowkes 2011: 8).

The international literature recognises that quasi-markets are subject to risk selection (Bonvin 2008; Struyven and Steurs 2005) and, in Australia, where continued funding is dependent on performance relative to all other agencies - as opposed to meeting agreed 'best practice' benchmarks or standards, for example - there are even greater incentives for agencies to engage in risk selection. Thus, despite ongoing efforts by the relevant Commonwealth Government department to eliminate such behaviour, risk selection continues to characterise employment services in Australia (Nevile 2013b: 67-68).

The introduction of quasi-markets for agencies whose work focuses on providing employment services for people with disability has lagged behind mainstream employment services, but, since 2004, when policy responsibility for open employment services was transferred from the social services department to the employment department, administrative and funding arrangements for disability employment have been gradually aligned with those of mainstream employment services. Consequently, despite new contracting arrangements introduced on 1 March 2010-designed to provide 'all eligible job seekers with access to individually tailored and comprehensive services ... to help participants obtain and maintain suitable employment' (Australian Government n.d., cited in Nevile and Lohmann 2011: 22) - agency capacity to deliver flexible, individualised services has decreased because aligning the administrative and funding arrangements of disability employment services (DES) with those of mainstream employment services has led to a complex, prescriptive 
and constantly changing administrative system and a funding structure that encourages agencies to focus on jobseekers who are more work ready (Nevile 2013a). ${ }^{2}$

Those working in the sector fully support the government's focus on outcomes, but remain concerned that despite successive government commitments to increase the participation of people with disability in open employment, the gap between participation rates for Australians without disability and those with disability has not decreased significantly for women and men with mild disability and has increased slightly for women and men with severe and profound disability (Kavanagh et al. 2013: 4-5). Only 40 per cent of DES jobseekers manage to obtain employment, and only 23 per cent manage to maintain their employment for 26 weeks (DSS 2014). At the same time, there is increasing recognition beyond the disability employment sector that services for people with disability should take a 'person-centred' approach (Nevile 2013a).

Needham (2011: 43) defines 'personalisation' as 'mechanisms that tailor services to specific circumstances of the individual', and goes on to note that '[p]ersonalised approaches share a common focus on outcomes rather than processes or outputs, often encompassing less quantitative aspects such as befriending, building relationships and broader quality of life issues'. However, an emphasis on building relationships means that processes cannot be ignored because processes mandated by a particular contracting regime may inhibit the development of beneficial and valued relationships. For example, those working in DES agencies report that:

We used to be able to get to know our clients on a different level. Now they are just - and it is horrible to have to say — but they are just like cows that are waiting - 'next', 'next'. You don't have time to get to know them and what motivates them. (Employment consultant, cited in Nevile 2013a: 154)

2 In February 2014, policy responsibility for DES was transferred back to the Department of Social Services (DSS). DSS is currently considering the nature of DES post 2018. The extent to which DSS is prepared to move DES funding and administrative arrangements away from those regulating mainstream employment services is not yet clear. 
While DES jobseekers value being treated 'as a person, not a number' (Nevile 2013b: 73), for government, the importance of taking a personcentred approach lies in the fact that achieving desired outcomes in coproduced services such as disability employment is, at least partly, dependent on how jobseekers and workers are assisted to find work and sustain their employment.

\section{The relationship between personalisation and achieving desired outcomes}

As part of an Australian Research Council (ARC) Linkage Project (LP130100288), which developed indicators of service quality for disability employment services, DES jobseekers were asked what they valued. What was very clear from the survey results was that jobseekers highly valued outcomes (92 per cent identified that they wanted a job), but they also highly valued how those outcomes were achieved, and an important element in the process of finding employment was their relationship with the service provider. For example, 86 per cent said they valued having a choice about the sort of work they did. Jobseekers also valued employment consultants who listened to what they had to say (78 per cent) and helped them to feel confident about their abilities (74 per cent). The fact that jobseekers valued being given a choice about the sort of work they do is hardly surprising. A recent study by Burchardt et al. (2015: 61) on the degree of autonomy individuals experience in various aspects of their life concluded that disability was associated with low levels of choice and control across all domains, including employment; and evaluations of direct payments and other forms of personal budgets or consumer-directed care report high levels of satisfaction from service users because they are able to exercise some degree of choice and control (see, for example, Netten et al. 2012: 1563; Needham 2011: 49; Stevens et al. 2011: 266; Fisher et al. 2010: viii; Ottmann et al. 2009: 471; Daly et al. 2008: 20; Kremer 2006: 399).

The economic, social and health effects of employment are well documented, as are the negative effects of unemployment on feelings of well-being, with the negative effects of unemployment occurring at the onset and during extended periods of unemployment (Courts et al. 2014: 466, 469). Thus, the longer individuals are unemployed, the higher is the psychological cost of job search activities (Krueger and 
Mueller 2011: 46). In other words, because the majority of jobseekers want to work, continued unsuccessful job search activity leads to increased feelings of sadness or depression:

Maybe I shouldn't say this, but I suppose I can understand because Centrelink put so much pressure on you to get a job, I can understand why there are so many suicides, because you tend to get so depressed about sending out resume after resume and getting [rejection] letters back. (Jobseeker, cited in Nevile 2013a: 152)

At the same time, individuals with higher levels of subjective wellbeing are more likely to be successful in gaining employment than those with lower levels of subjective well-being (Saloniemi et al. 2014: 533; Andersen 2008: 451).

While different theories have been put forward to explain the relationship between unemployment and subjective well-being, the loss of control that accompanies unemployment has been identified as a major reason for its negative effects on subjective wellbeing (Creed et al. 2012: 697). General psychological theories that have been applied to unemployment shed further light on the links between loss of control, decreased levels of subjective well-being and a reduced probability of re-employment. Expectancy-value theory is a cognitive motivation theory that relates the strength of an individual's motivation to strive to achieve a certain goal to their expectations of success (Vansteenkiste et al. 2005: 270). In the labour market context, expectancy-value theory predicts that unemployed jobseekers who have confidence (expect) that they will perform well in a job interview will put more effort into job search activities than those with lower expectations. A meta-review of studies that test the expectancyvalue theory in relation to labour markets confirms this hypothesis (Vansteenkiste et al. 2005: 270-71). Furthermore, jobseekers who have confidence in their ability to search for jobs are more likely to be successful in gaining employment than jobseekers with lower levels of self-efficacy (Duffy et al. 2013: 55).

The implication of these findings is that employment assistance that includes activities designed to enhance jobseekers' confidence in their own abilities will be more effective than programs that do not contain such elements: 'The challenge for practitioners is to provide strategies for unemployed people that will allow them to maintain high levels 
of job seeking, while at the same time maintain their psychological health and optimism. Increasing feelings of control are likely to be helpful with this' (Creed et al. 2012: 698).

Recent studies provide support for Creed et al.'s (2012) assertion that interventions that address psychological barriers will increase the probability of jobseekers gaining employment (see, for example, Maguire et al. 2014: 309).

While expectancy-value theory highlights the importance of motivation in achieving desired behaviours, and hence outcomes, self-determination theory argues that different types of motivation will lead to different outcomes. When applied to unemployed individuals, self-determination theory predicts that individuals who are intrinsically motivated will put more effort into job search activities and persist for longer than individuals who undertake job search activities because they feel obliged to do so (Vansteenkiste et al. 2004: 346).

What is particularly important for countries such as Australia with compliance-centred regimes is that when extrinsic motivation comes to be accepted by an individual as personally important (identified autonomous motivation), it has the same effect as intrinsic autonomous motivation (Vansteenkiste et al. 2005: 272). In other words, increased employment outcomes are possible in compliance-centred regimes that rely on controlled motivation if employment consultants/support workers are given the opportunity to assist jobseekers and workers turn controlled motivation into identified motivation. With its dual focus on both outcomes and processes that increase the likelihood of desired outcomes, personalisation is one way in which controlled motivation can be turned into identified autonomous motivation.

\section{Operationalising person-centred approaches}

Personalisation can be put into effect through direct cash payments or some form of voucher system whereby eligible service users are able to 'purchase' social goods in a competitive market. Allowing service users to choose their service provider should, in theory, make service providers more responsive to the needs of individual service users 
and hence lead to the provision of more flexible, responsive services. Thus, in theory, voucher systems also allow more choice for service providers in terms of how policy goals are achieved.

In the area of DES, the potential benefit of a voucher systemthe provision of more flexible and individualised services-is uncontroversial. As noted earlier, this is an explicit goal underlying previous changes in contracting arrangements and something that service providers would like to be able to provide. Furthermore, a quasi-market in DES already exists, as do design elements, such as eligibility criteria and a payment structure that reflects differing levels of need and type of service, and the government has already transferred significant financial risk on to service providers in that it does not guarantee a specific number of referrals and service provider agencies face the real prospect of contract termination or reduction in market share if their performance falls relative to all other agencies. Indeed, the level of financial risk service provider agencies are now expected to bear has meant a reduction in the number and diversity of service delivery agencies. For example, over the years the number of DES providers has fallen from about 350 to about 100.

Voucher systems, or proposals to introduce such systems, often attract vociferous debate, much of it ideological (Belfield and Levin 2005) - in part, because vouchers are simply a policy tool that can be used to expand or contract the welfare state (Daniels and Trebilcock 2005: 2). In other words, vouchers or other forms of person-centred approaches are not, in themselves, a remedy for inadequate funding, nor will they overcome supply constraints that arise from low population density. For example, in the United Kingdom, cost saving was a key theme in the personalisation narrative (Needham 2011: 51) and, over the years, critics of individual budgets have argued that the promise of improvements in service quality has been undermined by a funding model that simply reallocated 'generally inadequate funding within arbitrary and unhelpful eligibility criteria and means testing' (Beresford 2011-12: 40). In 2010, the UK Audit Commission concluded that 'personal budgets are unlikely to result in significant cost savings for councils' (cited in Wilberforce et al. 2012: 255) - a conclusion that echoes findings from a broader evaluation of personal budgets that additional transaction costs were associated with personal budgets, with service providers arguing that the only way they could offer more personalised services was if they were able to determine the price for 
their services, rather than the price being set by the local authority (Wilberforce et al. 2012: 253). As well as potentially affecting service quality, underfunding also constrains the salaries available to those providing personalised care, which in turn increases the difficulties involved in recruiting sufficient staff, particularly in rural areas (Baxter et al. 2013: 405; Glendinning 2012: 297; Cowen et al. 2011: 34).

Thus, as a comparative study of cash-for-care programs in four European countries noted, 'merely switching from direct service provision ... to cash payments does not in itself enhance choice and control' (Timonen et al. 2006: 468). The extent to which voucher systems deliver more choice to service users and more flexible, individualised services depends on the way in which such schemes are regulated. Active restriction of choice is often justified on the grounds of accountability, while passive restriction of choice occurs through information asymmetry, and as a consequence of the particular funding model adopted. The next section discusses these issues in more detail.

\section{Policy preconditions}

\section{The relationship between choice and accountability}

The concept of choice is central to the discourse surrounding personalisation, with choice seen as important-both as an end in itself and as a means to other policy-oriented ends. Many people with disability value choice for intrinsic reasons: in choosing, they are able to exercise control and agency, and being able to exercise control and agency is valued in itself, regardless of the policy outcome (Nevile 2009: 82; 2013a: 152). Theoretical approaches that value choice for intrinsic reasons are based on a range of philosophical positions, from neoliberal or libertarian perspectives to Amartya Sen's capability approach. For example, in an address to the National Press Club in November 2013, Mitch Fifield, then assistant minister with responsibility for disability in the Liberal National Party (LNP) Coalition Government, noted that 'the design at the heart of NDIS - the individual at the centre and in control being able to choose the supports of their choice - could not rest more easily with the philosophy of my party' (Fifield 2013). 
For some, intrinsic justifications of choice sit easily with particular extrinsic justifications. For example, many people with disability, academics and commentators have argued that choice is a fundamental prerequisite for realisation of social inclusion, citizenship and human rights (Hall 2009: 46; Glendinning 2008: 459; Spandler 2004: 192).

Those who care for a family member with disability tend to value choice for instrumental reasons - that is, if carers are given a choice and provided with the means to realise that choice, they can access services that best suit the needs of their family member: 'Having control over the money is the best way of giving people power. Otherwise we are forever fitting (or not fitting) into programs and services that might not suit us but which are all that is on offer' (Sally Richards, cited in Productivity Commission 2011: 354).

Or they can provide experiences for their family member that enrich that person's life:

Tim turned 21 and, like any young man, he's entitled to ... a 21 st birthday. [Under self-directed funding,] I was able to employ [someone] ... to do some social education informally with him in preparation for his 21 st birthday. It worked sublimely. He got the issue, even though his cognitive capacity is quite limited ... and he had a ball. (C. Quinn, cited in Productivity Commission 2011: 371)

For politicians and bureaucrats, instrumental justifications for choice can be particularly powerful. For example, politicians in the United Kingdom have embraced the notion that to attract and secure political legitimacy, public services need to offer service users (consumers) the same level of choice as is offered by the private sector (Glendinning 2008: 458). In its Inquiry Report, Disability care and support, the Productivity Commission (2011: 357) argued that 'an absence of genuine choice tends to result in lower quality and more costly services, less product variety and less innovation' because the ability of service users to act like consumers broadens the scope for competition and hence provides greater pressure for responsive, high-quality services.

Policy narratives that succeed in legitimising a certain course of action and that mobilise support across different national and international agencies by taking bits and pieces of different agendas and burying differences do not, however, provide good guides to action because the logic of political mobilisation and the logic of implementation 
are different (Mosse 2004: 663). For this reason, the implications of differing justifications usually manifest when broad policy goals (more choice) are translated into specific program design parameters. As Burchardt et al. (2015: 47) noted, the dominance of instrumental justifications in policy discourse means that governments are happy to give service users a choice between different providers, but choice over outcomes is usually limited or non-existent. For example, an evaluation of 13 individual budget trial sites in the United Kingdom found that while individual budget holders reported greater feelings of control over daily life, choice was constrained by decisions made by service delivery staff over what constituted a legitimate use of public funds (Stevens et al. 2011: 268). When the Netherlands introduced the option of personal budgets for individuals receiving care in the home in 1995, concerns about the accountability of clients meant that the scheme was tightly regulated. The resulting complexity discouraged some individuals from participating in the program and one-third of those who did participate outsourced all administrative requirements associated with the personal budget to care professionals paid by the state (Kremer 2006: 391).

Choice can also be restricted by concerns about the capacity of service users to exercise choice or a concern that they may make 'suboptimal' choices. For example, in the United Kingdom, the low rate of participation of people with learning disabilities in direct payments was due to the belief in some social service departments that people with learning disabilities do not have the competence or capacity to manage direct payments, with the result that people with learning disabilities were not actively encouraged to participate in the scheme (Hall 2009: 49). Similarly, in the Netherlands, when people with disabilities were first provided with a personal labour re-integration budget, some case managers did not inform eligible clients about the voucher scheme because they believed they were not capable of managing their own budget (Bosselaar and Prins 2007: 115). In Australia, information from those involved in the NDIS trial sites indicates that low expectations are, at times, restricting the choices of those involved in the scheme (De Natris 2015). In other words, an overly cautious approach to accountability and risk management concerns may result in 'individuals not being supported to make choices and take control' (Carr 2011: 16). 


\section{Information asymmetry}

Passive restriction of choice occurs when service users do not have sufficient information to make an informed choice about which service provider is best for them. As noted earlier, there is little publicly available information on the performance of disability employment agencies. The star ratings system was originally developed for this purpose, but has only ever been used as a performance management tool. While the star ratings system provides a simple, composite measure of performance, the method by which ratings are generated is complex, opaque and difficult to understand for both service providers and users. A further problem with the star ratings system is that it contains no information about the way in which outcomes are generated-information that is important for service users. In other words, confronted with a single number, service users have no idea whether a five-star service provider achieved this ranking through engaging in risk selection or whether they do indeed provide highquality services. In addition, the comparative nature of the star ratings system is of little use to service users who are only interested in the relative performance of service provider agencies in the city or local area in which they live (Wright 2008: 27).

In the case of DES, the problem of information asymmetry is relatively easy to overcome. The new indicators of service quality developed through LP130100288, and based on what jobseekers and workers value, together with information on employment outcomes, provide clear, simple and easy to understand information on both process and outcomes. ${ }^{3}$ While service provider agencies could publicise information that was not a true reflection of agency performance, dissatisfied service users are free to leave the agency and, over time, word of mouth would mean an agency that consistently inflated performance measures would suffer reputational damage. As one UK service provider observed when asked whether a move away from

3 Service provider agencies could make the following information publicly available and update it annually or every six months: the percentage of jobseekers and workers who feel able to take control of their lives in relation to seeking, gaining and maintaining work; the percentage of jobseekers and workers who feel confident about their abilities in relation to seeking, gaining and maintaining work; the number of jobseekers who have been placed in a job in the past six months; and the number of workers who have remained in that job for 13 weeks, 26 weeks or longer than 26 weeks. 
block contracts would mean a loss of business: '[t]he people who need to worry are those who are currently providing rubbish services' (cited in Wilberforce et al. 2012: 254).

Being supported to make choices and take control involves the provision of information about different service providers, but it also involves providing the opportunity for individuals to think about what it is they want, 'based on a rich understanding of what might be possible' (Burchardt et al. 2015: 62). As the NDIS example indicates, providing such opportunities may require training frontline staff involved in assessment and decision-making processes and establishing service delivery systems that are person-centred and relationship-based rather than systems that focus on process auditing and administration (Carr 2011: 15).

\section{The funding model}

Passive restriction of choice can also occur when procurement strategies restrict supply - for example, having a limited number of licensed or accredited providers from which service users can choose (Carr 2011: 13) or funding models that do not provide incentives to tailor services to individual needs (Wilberforce et al. 2011: 596). For this reason, the continued development of quasi-markets is essential. In the case of DES, the current quasi-market needs to be deregulated, with agency ability to continue operating dependent on business decisions taken by the agency rather than by government. Entry into the market would be dependent on passing a licensing or accreditation process, as is currently the case with aged care facilities.

As noted earlier, person-centred approaches raise particular accountability concerns in relation to potential choices made by service users, but also encompass concerns about the actions of service providers in terms of providing quality services. Concerns about the actions of service providers are particularly prevalent in debates over the effectiveness of school voucher programs, with government regulation seen as necessary to maintain service quality in the form of national education standards (Ladd 2003: 20). While public interest in the outcomes of various social care programs is not as intense as interest in educational outcomes, the existence of risk selection means that the question of whether governments should regulate the behaviour of service providers needs to be considered. 
Under the current contracting regime for DES, government control over the actions of service providers significantly restricts the ways in which service providers can assist jobseekers. Conceptualising their relationship with service providers in terms of agency theory means that governments fail to recognise the fact that DES staff see themselves as professionals with responsibility for acting in accordance with professional standards (Nevile 2013b: 68). The strength of these professional standards is clearly evident in the understanding DES staff have of the importance of relationships in terms of achieving desired outcomes, and the processes that allow those respectful, supportive relationships to be developed and maintained:

My clients respond to being treated with respect because this is one of the few places they're actually going to get it. If I'm going to make someone believe that they can do something, that takes time and it also requires me listening to them and knowing that. (Employment consultant, cited in Nevile 2013b: 74)

The desire of service providers to be treated as professionals requires a recalibration rather than an abandonment of accountability mechanisms. All DES agencies are required to comply with national disability service standards and are audited by independent qualityassurance auditors every three years to ensure compliance with all standards. Surveillance audits against some, but not all, of the standards are carried out in the intervening two years. Because the disability service standards were developed and updated through a consultative process that included service providers and service users, they are consistent with service providers' professional norms, and hence service providers are happy to be held to account through the national standards.

As noted earlier, the performance management framework can significantly affect the incentives to engage in risk selection, as can the payment structure. For example, when Germany introduced placement vouchers for jobseekers who had been unemployed for more than three months or who signed up for a job creation program, the private placement agency received half the value of the voucher once the jobseeker had been in work for six weeks, with the remaining amount paid when the individual had been in employment for six months. A payment system that only rewards outcomes creates incentives for agencies to focus attention on easier to place jobseekers, with the German Federal Audit Court concluding that the placement vouchers 'could be seen as windfall gains for recruitment agencies, 
since they would have placed the job seeker in question even if the bonus had not been available' (Bruttel 2005: 394). Payment systems that include payments on completion of interim milestones, such as improvements in confidence, are more likely to reduce the possibility of risk selection.

However, even when interim milestones are rewarded, there remains the issue of the weighting attached to the interim milestones compared with outcome payments. While there is no risk-free solution to this question, one possible solution is to allocate 40 per cent of an individual's payment to interim milestones, specified through a joint planning process, and 60 per cent to outcomes.

The difficulties involved in determining the level of assistance needed by each individual raise the question of whether agencies should be free to charge more for their services than allocated by government. The majority of DES users are obliged to look for work and, being dependent on government payments, have little or no capacity to topup allocated entitlements. Under the current system, DES agencies are able to assist people who are not eligible for employment service support (for example, individuals who are assessed as having a work capacity of zero to seven hours per week) but who come to the agency through direct registrations. That is, they are not referred by Centrelink, but choose to come because they want to work and have heard about the agency or have had contact with the agency while still at school. It is important that the ability of DES agencies to assist such individuals is not diminished, particularly when the NDIS is rolled out across Australia. Giving agencies the autonomy to determine the price of their service for direct registrations could be one way of increasing economic participation for all Australians with disability.

An explicit voucher system in the form of a smart card would facilitate payment on completion of agreed milestones and outcomes and would also make it easier for service users to move to another provider if they become dissatisfied with their current provider. While use of a smart card has the potential to reduce the transaction costs associated with voucher schemes, it would not eliminate them entirely. Under the current contracting regime, however, service providers have to spend a significant amount of time meeting departmental reporting requirements and it is likely that the introduction of a voucher system in a deregulated market would lead to a reduction in time spent on administration and compliance activities. 


\section{Conclusion}

In this chapter I have argued that the introduction of an explicit voucher system for DES with entry into the market through a licensing or accreditation process will increase the capacity of service providers to deliver what government, service providers and service users want: flexible, individualised services and improved employment outcomes.

\section{References}

Andersen, S. H. 2008. 'The short- and long-term effects of government training on subjective well-being.' European Sociological Review 24(4): 451-62.

Baxter, K., P. Rabiee and C. Glendinning. 2013. 'Managed personal budgets for older people: What are English local authorities doing to facilitate personalized and flexible care?' Public Money and Management 33(6): 399-406.

Belfield, C. and H. M. Levin. 2005. 'Vouchers and public policy: When ideology trumps evidence.' American Journal of Education 111(4): 548-67.

Beresford, P. 2011-12. 'Are personal budgets necessarily empowering for service users? If not, what's it all about?' Research, Policy and Planning 29(1): 37-43.

Bonvin, J.-M. 2008. 'Activation policies, new modes of governance and the issue of responsibility.' Social Policy and Society 7(3): 367-77.

Bosselaar, H. and R. Prins. 2007. 'Personal return to work budgets for persons with disabilities: Demand-based delivery of re-integration services in The Netherlands.' European Journal of Social Security 9(2): 111-25.

Bruttel, O. 2005. 'Delivering active labour market policy through vouchers: Experiences with training vouchers in Germany.' International Review of Administrative Sciences 71(3): 391-404. 
Burchardt, T., M. Evans and H. Holder. 2015. 'Public policy and inequalities of choice and autonomy.' Social Policy and Administration 49(1): 44-67.

Carr, S. 2011. 'Personal budgets and international contexts: Lessons from home and abroad.' Journal of Care Services Management 5(1): 9-22.

Courts, A., K. Lehmann and M. Hood. 2014. 'The health and wellbeing effects of active labor market programs.' In Interventions and Policies to Enhance Wellbeing: A complete reference guide. Volume VI, eds F. A. Huppert and G. L. Cooper, 465-82. Chichester, UK: Wiley Blackwood.

Cowen, A., P. Murray and S. Duffy. 2011. 'Personalised transition: A collaborative approach to funding individual budgets for young disabled people with complex needs leaving school.' Journal of Integrated Care 19(2): 31-36.

Creed, P., M. Hood and L. Y. Leung. 2012. 'The relationship between control, job seeking, and well-being in unemployed people.' Journal of Applied Social Psychology 42(3): 689-701.

Daly, G., A. Roebuck, J. Dean, F. Goff, M. Bollard and C. Taylor. 2008. 'Gaining independence: An evaluation of service users' accounts of the individual budgets pilot.' Journal of Integrated Care 16(3): $17-25$.

Daniels, R. J. and M. J. Trebilcock. 2005. Rethinking the Welfare State: The prospects for government by voucher. London: Routledge.

De Natris, P. 2015. Address to the NDS Disability at Work Conference. Melbourne, 19 May.

Department of Social Security (DSS). 2014. Evaluation of Disability Employment Services 2010-2014. Canberra: Australian Government.

Duffy, R. D., E. M. Bott, B. A. Allan and C. L. Torrie. 2013. 'Examining a model of life satisfaction among unemployed adults.' Journal of Counselling Psychology 60(1): 53-63.

Fifield, M. 2013. Address to the National Press Club. Canberra, 20 November. 
Fisher, K., R. Gleeson, R. Edwards, C. Purcal, T. Sitzek, B. Dinning, C. Laragy and D. Thompson. 2010. Effectiveness of individual funding approaches for disability support. Occasional Paper No. 29. Department of Families, Housing, Community Services and Indigenous Affairs, Canberra.

Fowkes, L. 2011. 'Rethinking Australia's employment services.' Perspectives. Whitlam Institute, Sydney.

Glendinning, C. 2008. 'Increasing choice and control for older and disabled people: A critical review of new developments in England.' Social Policy and Administration 42(5): 451-69.

Glendinning, C. 2012. 'Home care in England: Markets in the context of under-funding.' Health and Social Care in the Community 20(3): 292-99.

Hall, E. 2009. 'Being in control: Personal budgets and the new landscape of care for people with learning disabilities.' Mental Health Review Journal 14(2): 44-53.

Kavanagh, A., L. Krnjacki, A. Beer, A. La Montagne and R. Bentley. 2013. 'Time trends for socio-economic inequalities for women and men with disabilities in Australia: Evidence of persisting inequalities.' International Journal for Equity in Health 12(73): 1-10.

Kremer, M. 2006. 'Consumers in charge of care: The Dutch personal budget and its impact on the market, professionals and the family.' European Societies 8(3): 385-401.

Krueger, A. B. and A. Mueller. 2011. 'Job search, emotional well-being, and job finding in a period of mass unemployment: Evidence from high-frequency longitudinal data.' Brookings Papers on Economic Activity (Spring): 1-81.

Ladd, H. F. 2003. 'Introduction.' In Choosing Choice: School choice in international perspective, eds D. N. Plank and G Sykes, 1-23. New York: Teachers College Press.

McLucas, J. 2013. Senate summing up speech, National Disability Insurance Scheme Bill. 20 March. Parliament House, Canberra.

Maguire, N., V. C. Hughes, L. Bell, A. Bogosian and C. Hepworth. 2014. 'An evaluation of the choices for well-being project.' Psychology, Health \& Medicine 19(3): 303-15. 
Mosse, D. 2004. 'Is good policy unimplementable? Reflections on the ethnography of aid policy and practice.' Development and Change 35(4): 639-71.

Needham, C. 2011. Personalising Public Services: Understanding the personalisation narrative. Bristol: The Policy Press.

Netten, A., K. Jones, M. Knapp, J.-L. Fernandez, D. Challis, C. Glendinning, S. Jacobs, J. Manthorpe, N. Moran, M. Stevens and M. Wilberforce. 2012. 'Personalisation through individual budgets: Does it work and for whom?' British Journal of Social Work 42(8): 1556-573.

Nevile, A. 2009. 'Values and the legitimacy of third sector organisations: Evidence from Australia.' Voluntas 20(1): 71-89.

Nevile, A. 2013a. 'Reframing rights as obligations: Implications for service users' ability to exercise their rights.' Australian Journal of Human Rights 19(2): 147-64.

Nevile, A. 2013b. 'The curse of accountability: Assessing relationships in the delivery of employment services.' The Economic and Labour Relations Review 24(1): 64-79.

Nevile, A. and R. Lohmann. 2011. 'It is like they just don't trust us': Balancing trust and control in the provision of disability employment services. Available from: crawford.anu.edu.au/sparc/ pdf/2011/20110621_final_report.pdf (accessed 28 June 2016).

Ottmann, G., C. Laragy and M. Haddin. 2009. 'Experiences of disability consumer-directed care users in Australia: Results from a longitudinal qualitative study.' Health and Social Care in the Community 17(5): 466-75.

Productivity Commission. 2011. Disability care and support. Productivity Commission Inquiry Report No. 54, July. Productivity Commission, Canberra. Available from: pc.gov.au/projects/inquiry/ disability-support/report (accessed 7 January 2014).

Saloniemi, A., K. Romppainen, M. Strandh and P. Virtanen. 2014. 'Training for the unemployed: Differential effects in white- and blue-collar workers with respect to mental well-being.' Work, Employment and Society 28(4): 533-50. 
Spandler, H. 2004. 'Friend or foe? Towards a critical assessment of direct payments.' Critical Social Policy 24(2): 187-209.

Stevens, M., C. Glendinning, S. Jacobs, N. Moran, D. Challis, J. Manthorpe, J.-L. Fernandez, K. Jones, M. Knapp, A. Netten and M. Wilberforce. 2011. 'Assessing the role of increasing choice in English social care services.' Journal of Social Policy 40(2): 257-74.

Struyven, L. and G. Steurs. 2005. 'Design and redesign of a quasimarket for the reintegration of job seekers: Empirical evidence from Australia and the Netherlands.' Journal of European Social Policy 15(3): 211-29.

Timonen, V., J. Convery and S. Cahill. 2006. 'Care revolutions in the making? A comparison of cash-for-care programmes in four European countries.' Ageing \& Society 26(3): 455-74.

Vansteenkiste, M., W. Lens, H. De Witte and N. T. Feather. 2005. 'Understanding unemployed people's job search behaviour, unemployment experience and well-being: A comparison of expectancy-value theory and self-determination theory.' The British Journal of Social Psychology 44: 269-87.

Vansteenkiste, M., W. Lens, S. De Witte, H. De Witte and E. L. Deci. 2004. "The "why" and "why not" of job search behaviour: Their relation to searching, unemployment experience, and well-being.' European Journal of Social Psychology 34: 345-63.

Wilberforce, M., K. Baxter and C. Glendinning. 2012. 'Efficiency, choice and control in social care commissioning.' Public Money and Management 32(4): 249-56.

Wilberforce, M., C. Glendinning, D. Challis, J.-L. Fernandez, S. Jacobs, K. Jones, M. Knapp, J. Manthorpe, N. Moran, A. Netten and M. Stevens. 2011. 'Implementing consumer choice in long-term care: The impact of individual budgets on social care providers in England.' Social Policy and Administration 45(5): 593-612.

Wright, S. 2008. Contracting our employment services: Lessons from Australia, Denmark, Germany and the Netherlands. CPAG Policy Briefing. Child Poverty Action Group, London. 
This text is taken from The Three Sector Solution: Delivering public policy in collaboration with not-for-profits and business, edited by John Butcher and David Gilchrist, published 2016 by ANU Press, The Australian National University, Canberra, Australia. 